\title{
Research Paper: Mediation Role of Emotion Regulation Between Procrastination, Psychological Wellbeing, and Life Satisfaction in the Elderly
}

\author{
Narges Pirzadeh Nouri' ${ }^{1}$, Mostafa Asheghi ${ }^{2}$, Mehdi Asheghi $^{3}$, Mohsen Hesari $^{1^{*}}$ (1) \\ 1. Department of Clinical Psychology, Faculty of Medicine, Shahid Beheshti University of Medical Sciences, Tehran, Iran. \\ 2. Depattment of Industrial and Organizational Psychology, Faculty of Educational Sciences and Psychology, Shahid Chamran University of Ahvaz, Ahvaz, Iran \\ 3. Department of School Counseling, Faculty of Psychology and Educational Sciences, Allameh Tabataba'i University, Tehran, Iran.
}

\begin{tabular}{|c|c|}
\hline $\begin{array}{l}\text { Use your device toscan } \\
\text { and read the article online }\end{array}$ & 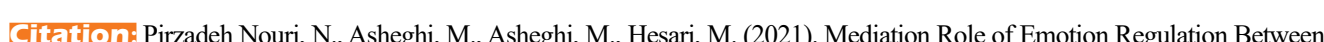 \\
\hline 口iting & $\begin{array}{l}\text { Procrastination, Psychological Wellbeing, and Life Satisfaction in the Elderly. Journal of Practice in Clinical Psychology, 9(2), } \\
\text { 111-120. https://doi.org/10.32598/jpcp.9.2.716.2 }\end{array}$ \\
\hline 回促地 & doil https://doi.org/10.32598/jpcp.9.2.716.2 \\
\hline
\end{tabular}

\section{(c) (i) (9)}

Article info:

Received: 02 Dec 2020

Accepted: 25 Feb 2021

Available Online: 01 Apr 2021

Keywords:

Emotion regulation,

Procrastination, Psychological wellbeing, Life satisfaction, Elderly

\section{ABSTRACT}

Objective: Successful and healthy aging is the most critical outcome and policy of decisions in the elderly population. Paying attention to the elderly as well as their life satisfaction and wellbeing can be beneficial for this stratum. Among the influencing characteristics of successful aging and life satisfaction in the elderly is their ability to having active social relationships and feeling useful. Accordingly, the ability to regulate emotions can affect wellbeing and life satisfaction and reduce procrastination in the elderly. Therefore, the present study aimed to investigate the relationship between procrastination, Psychological Wellbeing (PWB), and Life Satisfaction (LS) mediated by Emotion Regulation (ER) in the elderly.

Methods: The study participants included 260 elderly in Tehran City, Iran, who were selected by convenience sampling method. The research tools included the Satisfaction With Life Scale (SWLS), Ryff's Psychological Wellbeing (PWB) Scale, the Tuckman Procrastination Scale (TPS), and the Emotion Regulation Questionnaire (ERQ).

Results: The obtained results signified the mediating role of ER in the direct and indirect relationship between procrastination and LS, and enhanced PWB in the explored elderly. Structural equation modeling analyses data demonstrated the fit of the proposed model.

Conclusion: Solutions can be provided to reduce procrastination and increase offer skills in the elderly; accordingly, their LS and PWB could be improved by practical training and holding workshops in this respect.

\section{Corresponding Author:}

Mohsen Hesari, MSC.

Address: Department of Clinical Psychology, Faculty of Medicine, Shahid Beheshti University of Medical Sciences, Tehran, Iran.

Tel: +98 (935) 3869094

E-mail: mohsenhesari@sbmu.ac.ir; mohsenhesari72@yahoo.com 


\section{Highlights}

- There was an adverse relationship between procrastination and life satisfaction, and wellbeing in the studied elderly.

- Life satisfaction and wellbeing were positively correlated with emotion regulation skills in the explored elderly.

- Emotion regulation skills, as a positive personal reassures, can significantly decrease procrastination and increase psychological wellbeing and life satisfaction in the elderly.

\section{Plain Language Summary}

Successful and healthy aging is the major outcome and policy of decisions in the elderly. Successful aging includes many elements, like psychological aspects, such as mindfulness, family relationships, and social connecting. Some researchers see well-being as a potential complement to life and happiness; while others consider it as the individual's experience of accomplished goals and accepting emotional experiences, whether pleasant or unpleasant. They believe it provides important information for personal growth and prosperity and even wellbeing and comfort in one's life. Moreover, having diverse emotion regulation skills predicts more life satisfaction and fewer psychological disorders in people with these skills. The elderly with a higher feeling of wellbeing experience greater positive emotions. Besides, they have a positive evaluation of the past and events or any other happening around them. As a result, the person experiences more life satisfaction. Considering issues, like procrastination, as well as the importance of aging and psychological wellbeing provides a better life for the elderly. This study suggested the role of emotion regulation in life satisfaction and increasing the psychological wellbeing of the elderly. Therefore, using the results of this study, solutions can be provided to engage the elderly in useful activities and reduce procrastination among them; accordingly, we could increase their life satisfaction and overall quality of life by practical training and holding related workshops.

\section{Introduction}

rocrastination is defined as a lack of self-regulatory function and a behavioral tendency to delay what is necessary for achieving a goal (Ferrari \& Díaz-Morales, 2007). The lack of self-control reduces the willpower and increases the procrastination of individuals. Procrastination causes great hardship and suffering in individuals' lives; however, little research and therapeutic interventions have been presented to solve it. Numerous characteristics are usually associated with general procrastination (Zhao et al., 2019). The concept of procrastination refers to the deliberate and the irrational delay of action despite being aware of its destructive effects (Simpson \& Pychyl, 2009); thus, it should not be mistaken for laziness. This definition is based on the assumption that an individual designs specific tasks to perform. However, when it comes to performing the tasks, they change the schedule and pursue other pleasurable behaviors (Steel, 2007). Among extant approaches to procrastination research, previous studies found several of its correlates. These variables include personality traits, such as impulsivity, neuroticism, and conscientiousness (Schouwenburg and Lay, 1995) me- ta-analysis and review in Steel, 2007), as well as other constructs, including Emotion Regulation (ER), stress coping self-efficacy and motivation, and numerous other factors (Steel, 2007 for reviews). The present research focused on 3 factors related to procrastination; ER, Psychological Wellbeing (PWB), and Life Satisfaction (LS) in the elderly.

LS is among the main psychological needs of individuals. LS realty impacts the formation of personality and the way of living. LS has always been the focus of scholars, as a defining characteristic of fostering a positive attitude towards the world in which they live (Feldman, 2019). Contrary to popular belief, LS does not decrease with aging and remains constant throughout life. Aging is a time of maturity, proficiency, and an opportunity to enrich life and improve being satisfied with it. In 2018, for the first time, the population of 65 -year-olds and older increased beyond children under 5 years (Tal \& Kerret, 2020). This aging of the population and the increase in the number of the elderly pose challenges at the individual and social levels. Such complications include the significance of biopsychological health, economic sustainability, and attention to the financial issues of the elderly and retirees. They also highlight the need to care for this population in different societies. The main issue 
responsible for such an increase in the elderly is active aging (Ramia \& Voicu, 2020).

Another significant factor in procrastination is PWB. PWB is a complex and multidimensional structure; it is associated with accomplishing personal goals and the process of success which makes a person feel alive and part of the society (Rees, Goswami \& Bradshaw, 2010). According to Ryff, the structure of PWB has 6 dimensions, as follows: self-acceptance; personal growth; purpose in life; positive communication with others; mastery of the environment, and autonomy. PWB is known for proper interaction with the world, effective success, efficient success, and social cohesion over time (Gomes, Gonçalves \& Costa, 2015). Furthermore, PWB is a component of Quality of Life (QoL) that refers to the manner individuals evaluate life; it consists of cognitive and emotional dimensions. The cognitive dimension indicated the cognitive assessment of individuals' satisfaction with life. The emotional dimension reflects having maximum positive emotions and minimum negative emotions (Sirigatti, Penzo, Giannetti, Casale \& Stefanile, 2016).

Successful and healthy aging is the main outcome and policy of decisions in the elderly population (Michel \& Sadana, 2017). Successful aging is defined as aging with favorable biopsychological health and physical flexibility; the ability to live happily; and satisfactorily relationships with family. It covers psychological aspects, such as mindfulness, family relationship, and social connecting (Watakakosol et al., 2013), being more socially supportive, and more satisfied with life (Şahin, Özer \& Yanardağ, 2019).

The elderly with a greater PWB, experience more positive emotions. Additionally, they have a positive evaluation of the past and the events, or other happenings. As a result, the subject has a more psychological preparation to prevent and cope with problems. However, the elderly with low PWB encounter further depression and anxiety (Farhadi, Barazandeh Choqaiee, Mokhtappour, Karami \& Daraeezadeh, 2015). Therefore, considering the importance of the PWB in old age, it seems necessary to explore more effective factors in maintaining and creating it (Huxhold, Fiori, Webster \& Antonucci, 2020).

As per studies, procrastination plays a role in reducing PWB and other positive psychological characteristics (Duru \& Balkis, 2017). According to the theoretical background, procrastination is responsible for a complex interaction of behavioral, cognitive, and emotional factors (Scent \& Boes, 2014). Part of the characteristics associated with procrastination is demographic factors, like age. Studies revealed that the elderly use less active problem-solving skills and are more prone to procrastination than younger individuals.

Another essential variable related to PWB and procrastination is ER. The literature revealed that factors, like ER, are used to cope with stressors among the elderly (Bailey, Brady, Ebner \& Ruffman, 2020). Emotions play a critical role in various aspects of life, such as adapting to life changes and stressful events. ER is the process by which a subject compares their current emotional state with a desirable one. Subsequently, they adopt specific ER strategies to achieve the desired state (Ouellet, Langlois, Provencher \& Gosselin, 2019). Moreover, various studies documented that ER skills increase in individuals with aging (Perry, Donzella, Parenteau, Desiardins \& Gunnar, 2019; Cordes et al., 2019).

It is believed that accepting emotional experiences, whether pleasant or unpleasant, provides crucial information for personal growth and prosperity and even the experience of PWB and comfort in one's life (Ryan \& Deci, 2017). Besides, generating diverse ER skills predicts more LS and fewer psychological disorders in individuals (Chen, Chen \& Bonanno, 2018).

Considering the issues raised in this article and the importance of aging and those of PWB and a better life for the elderly, it seems necessary to pay attention to the variables influencing the successful aging and PWB of the elderly. Therefore, this study intended to explain the conditions of LS and PWB in the elderly. This purpose was achieved by designing a model of structural equations and investigating its relationship with procrastination with the mediating role of ER in the elderly. In our country, little research has been performed to explain LS and PWB in the elderly as a functional model. This study intended to assess the importance of the role of ER in PWB and LS in the elderly; we examined the relationship between these issues and procrastination in the elderly.

\section{Materials and Methods}

This was a correlational study (Gall, Borg, \& Gall, 2006) using a structural model (Figure 1). The statistical population of the present study included all the elderly in Tehran City, ran. Of whom, 260 subjects were selected to review the proposed model by convenience sampling method. The sample size of this study was determined by the number of parameters. According to Klein (1988), $\geq 10$ subjects are required to test the model per calculated parameter. In this study, based on the number of direct 


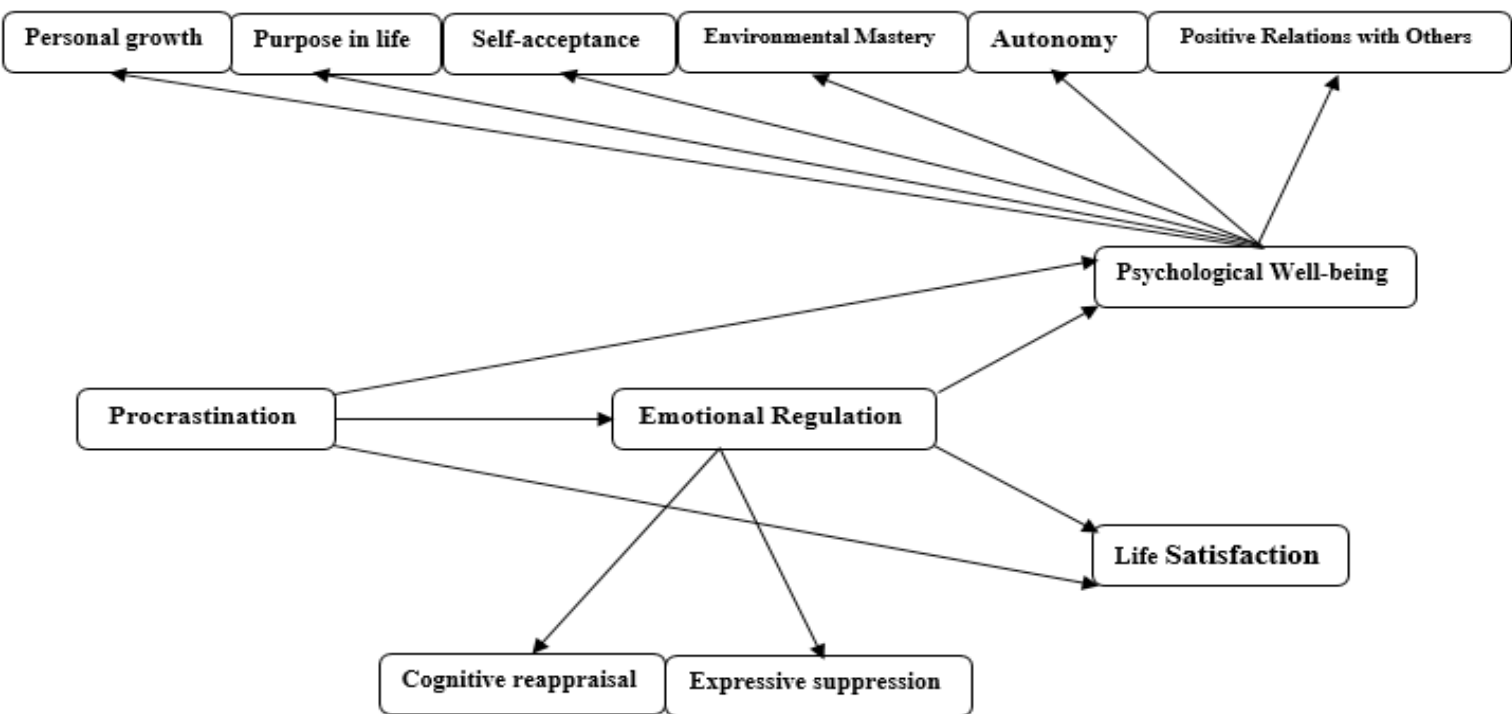

Figure 1. The suggested research model

paths $(n=12)$, the number of exogenous variables $(n=1)$, and the number of error variance $(n=11), 24$ parameters were calculated. According to the sample size of the present study $(\mathrm{N}=260)$, approximately 11 subjects were considered per parameter, indicating the adequacy of the sample to test the model.

The following measured were used in the present study.

The Satisfaction With Life Scale (SWLS) (Diener, Emmons, Larsen \& Griffin, 1985):

This short five-item scale measures an individual's overall cognitive judgments about satisfaction with life. This scale has been implemented on different samples and its various versions have been translated into multiple languages. Prior research (Pavot \& Diener, 1993) reported a high internal consistency for it. They reported Cronbach's alpha coefficient to range from 0.89 to 0.79 , with an overall correlation between 0.80 and 0.51 , as well as reliability of 0.83 . Furthermore, for two-month and longer periods, they reported a reliability of 0.50 for this scale. In the Iranian society and a study conducted on Azadshahr students, (Bayani, Goudarzi, Bayani \& Kouchaki, 2008) reliability of 0.83 was obtained using the Cronbach's alpha coefficient, and validity of 0.69 by the test-retest method. Additionally, the current study applied Cronbach's alpha coefficient to calculate the reliability coefficient of this scale. Accordingly, a value of 0.82 was obtained, suggesting the acceptable reliability of this questionnaire.

\section{Ryff's Psychological Wellbeing (PWB) Scale:}

This questionnaire was developed by Ryff in 1988 to assess the PWB of individuals. This questionnaire has 28 questions and 6 components that measure individuals' PWB on a five-point Likert-type scale (e.g. Did you feel completely well and healthy from last month until today?). It measures PWB in 6 dimensions, as follows: positive communication with others; autonomy, mastery of the environment; self-acceptance; purpose in life, as well as personal growth and development. Ryff reported the retest reliability of this scale in the American community to range between 0.81 and 0.86 . Ryff also reported the internal consistency of the test subscales from 0.86 to 0.93 (Bayani et al., 2008); in the Iranian student community, the PWB scale reached retest reliability of 0.82 .

In the present study, the Cronbach's alpha coefficient was used to calculate the reliability coefficient, which equaled 0.85 , reflecting the acceptable reliability of this questionnaire.

\section{Tuckman Procrastination Scale (TPS)}

The 16-item scale (Tuckman, 1991) is used to measure procrastination. Scoring in this test is based on a Likert-type scale from 1 to 4 (I totally agree to I totally disagree) with a high score as a sign of procrastination. Tuckman stated that the reliability of this questionnaire in the American society was measured as 0.86 . In a study by (Kazemi, Fayyazi \& Kaveh, 2010) on a Persian sample, Cronbach's alpha coefficient was calculated as 0.71 , signifying its appropriate validity in the country. In the 
Table 1. Descriptive findings and Pearson correlation coefficients of the research variables

\begin{tabular}{ccccccc}
\hline Row & Variable & Mean \pm SD & $\mathbf{1}$ & $\mathbf{2}$ & $\mathbf{3}$ & $\mathbf{4}$ \\
\hline 1 & Procrastination & $38.22 \pm 6.28$ & - & & \\
2 & Emotion Regulation & $28.82 \pm 5.28$ & $-0.46^{* *}$ & - & \\
3 & Psychological wellbeing & $89.62 \pm 12.79$ & $-0.55^{* *}$ & $0.48^{* *}$ & - \\
4 & Satisfaction with Life & $17.32 \pm 3.18$ & $-0.68^{* *}$ & $0.52^{* *}$ & $0.73^{* *}$ \\
\hline$* *$ Correlation & PRACTICE In PSYCH LOGY \\
\hline
\end{tabular}

present study, Cronbach's alpha coefficient was used to calculate the reliability coefficient, which equaled 0.7 , indicating the acceptable reliability of this questionnaire.

\section{Emotion Regulation Questionnaire (ERQ)}

The ERQ was designed and validated by Gross (2002). This questionnaire includes 10 types of answer packs, answered based on a five-point Likert-type scale. The ERQ measures the dimensions of suppression and reassessment. The internal consistency (Cronbach's alpha coefficient) of this questionnaire in Americans was measured as 0.81 and this questionnaire was validated in Iran (Beigzade, 2013) and a reliability of 0.74 was obtained for it. In the current study, Cronbach's alpha coefficient was used to calculate the reliability coefficient, which equaled 0.78 , suggesting the acceptable reliability of the questionnaire.

\section{Results}

The conceptual model of Figure 1 was analyzed by structural equation modeling using AMOS. To measure the fit of the proposed model, a combination of fit measures, such as relative Chi-squared $\left(\chi^{2} / \mathrm{df}\right)$, Incremental Fit Indices (IFI), Comparative Fit Index (CFI), Good Fit Index (GFI), Adjusted Goodness of Fit Index (AGFI), Tucker-Lewis Index (TLI), and Bentler-Bount Index, or the Normed Fit Index (NFI) were used.

Table 1 presents descriptive indices and correlation coefficients of the research variables. The correlation coefficient between the study variables was significant at $\mathrm{P}<0.01$.
Table 2 lists the fit of the proposed model based on fit indicators. Table 3 demonstrates the direct effects between the study variables. The indirect pathways were examined by the bootstrapping method in AMOS and the relevant data are illustrated in Table 4. The upper and lower limits of the coefficients of both pathways excluded the number zero; thus, both indirect pathways were significant. Therefore, ER mediates the relationship between procrastination, PWB, and LS. Figure 2 shows the standard coefficient for direct pathways in the proposed model.

As per Table 2, the goodness of fit indices, including relative Chi-squared $(\chi 2 / \mathrm{df}=3.51), \mathrm{IFI}=0.94, \mathrm{CFI}=0.94$, $\mathrm{GFI}=0.95$, AGFI $=0.95$, TLI $=93$, NFI $=0.92$, and RM$\mathrm{SEA}=0.07$ indicated a reasonable fit of the proposed model with the collected data. Thus, the proposed model provided a good fit.

\section{Discussion}

This study investigated the mediating role of ER in the relationship between procrastination, PWB, and LS of the elderly. The results highlighted an adverse relationship between procrastination, ER ( $\mathrm{P}=0.001, \beta=-0.18)$, PWB ( $\mathrm{P}=0.001, \beta=-0.34)$, and LS $(\mathrm{P}=0.001, \beta=-0.46)$. The obtained data also revealed a positive relationship between ER and PWB $(\mathrm{P}=0.001, \beta=0.22)$, and LS $(\mathrm{P}=0.001, \beta=0.28)$. Furthermore, the results signified the mediating role of ER in the relationship between procrastination, PWB, and LS in the elderly. These results were consistent with those of previous studies (Castell, Lluch, Ribas, Borràs \& Moltó, 2017; Beutel et al., 2016; Brown et al., 2020; Ocal, 2016; Perry et al., 2019).

Table 2. The fit of the proposed model based on the fit indicators

\begin{tabular}{lcccccccccc}
\hline Variable Fit Indices & $\mathbf{X}^{2}$ & df & $\mathbf{X}^{2} / \mathbf{d f}$ & GFI & AGFI & NFI & CFI & IFI & TLI & RMSEA \\
\hline Acceptable value & - & - & $<5$ & $>0.9$ & $>0.9$ & $>0.9$ & $>0.9$ & $>0.9$ & $>0.9$ & $<0.08$ \\
Proposed pattern & 168.58 & 48 & 3.51 & 0.95 & 0.95 & 0.92 & 0.94 & 0.94 & 0.93 & 0.07 \\
\hline
\end{tabular}




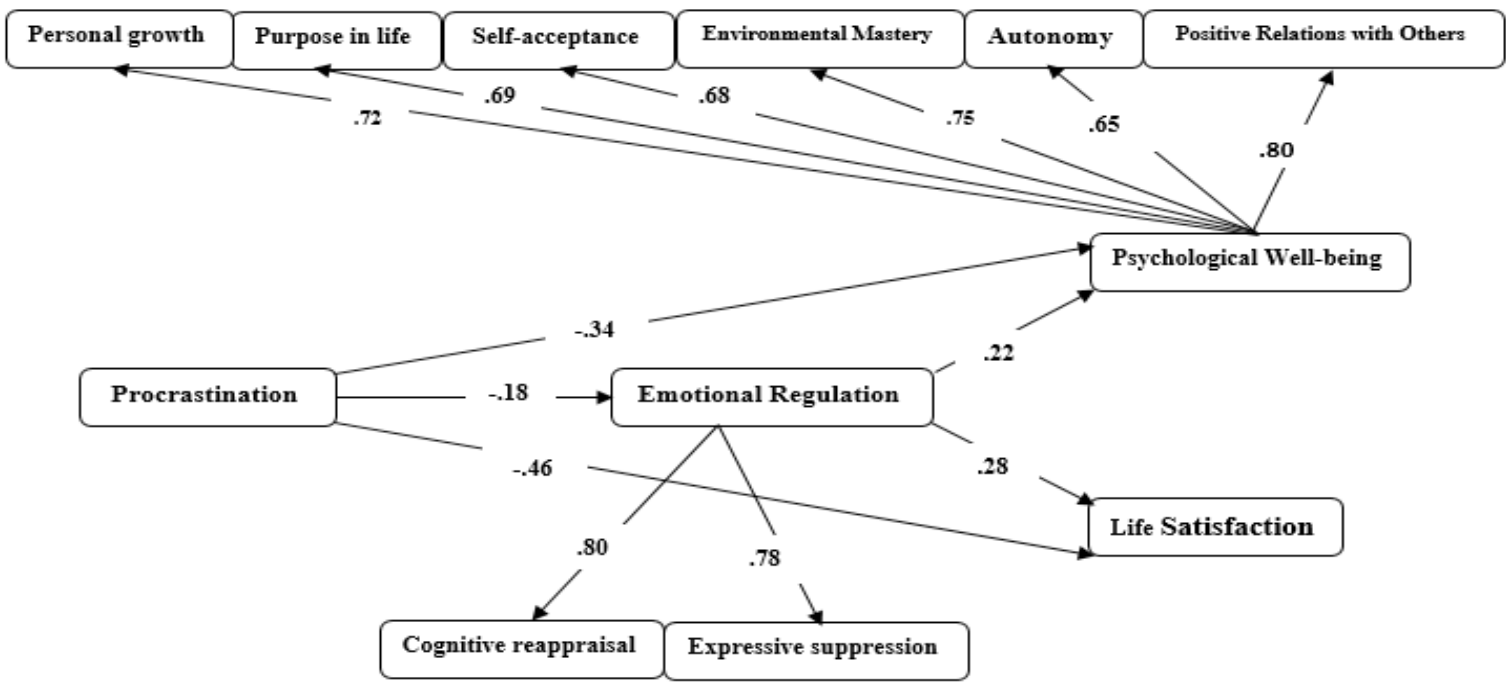

Figure 2. Standardized regression weights for the final model paths

CLINICAL PSYCH $\oplus$ LOGY

The participation of the elderly as a group full of experience at the community level is declining; the active presence of the elderly in the heart of society is also reduced. These issues make the elderly feel less secure in the community and increase the feeling of depression, isolation, and loneliness, leading to threatening their mental health. Accordingly, they lack PWB, which affects their LS (Ramia \& Voicu, 2020).

This study data addressed procrastination, as another essential factor influencing LS in the elderly, i.e., also emphasized by previous studies (Ocal, 2016; Aziz, Tariq, \& Zaidi, 2019). These researchers studied the age groups of young subjects, students, and the elderly. They concluded that procrastination negatively impacts individuals' LS. This procrastination and postponing tasks prevent the elderly from feeling positive about themselves and their lives; thus, they feel like not achieving what they wanted from life and are unsatisfied with the life they have spent. Additionally, studies presented that the elderly who, to some extent, participate in social activities and enjoy favorable social relationships are less likely to generate various diseases, especially mental health disorders (Yazdanbakhsh, 2016). Socioemotional processes affect health throughout life; however, such influences are more visible at the beginning and end of life when individuals are more vulnerable. Older people experience and interpret life events and have emotional reactions to these events; subsequently, these emotional reactions greatly impact the elderly's health and wellbeing (Charles \& Mavandadi, 2004). Research results revealed that individuals who use positive CER strategies develop greater psychological adjustment and wellbeing (Chen et al., 2018).

$\mathrm{ER}$ is also an effective source to reduce procrastination and increase PWB and LS (Benita, Benish-Weisman, Matos \& Torres, 2020; Huang, Lee \& Yang, 2019; Katana, Röcke, Spain \& Allemand, 2019; Sirois, Nauts,

Table 3. Parameters of direct effects between research variables in the research model

\begin{tabular}{cccccc}
\hline Parameters - Routes & Standard Estimate & Non-Standard Estimates & SD & Critical Ratio & Significance Level \\
\hline Procrastination $\rightarrow$ ER & -0.18 & -0.22 & 0.06 & -2.45 & 0.001 \\
\hline Procrastination $\rightarrow$ PWB & -0.34 & -0.42 & 0.22 & -3.99 & 0.001 \\
\hline Procrastination $\rightarrow$ LS & -0.46 & -0.31 & 0.12 & -5.21 & 0.001 \\
ER $\rightarrow$ PWB & 0.22 & 0.34 & 0.08 & 2.84 & 0.001 \\
ER $\rightarrow$ LS & 0.28 & 0.18 & 0.11 & 3.21 & 0.001 \\
\hline
\end{tabular}


Table 4. Bootstrap results for the mediating route of the proposed pattern of the present study

\begin{tabular}{lllcc}
\hline \multicolumn{1}{c}{ Routes } & Values & Sig. & $\begin{array}{c}\text { Confidence Interval } \\
\text { (upper Limit) }\end{array}$ & $\begin{array}{c}\text { Confidence Interval } \\
\text { (Lower Limit) }\end{array}$ \\
\hline Procrastination $\rightarrow$ ER $\rightarrow$ P PWB & -0.1259 & 0.001 & -0.0525 & -0.3252 \\
Procrastination $\rightarrow$ ER $\rightarrow$ LS & -0.2312 & 0.001 & -0.1009 & -0.4813 \\
\hline ER: Emotion regulation; PWB: Psychological wellbeing; LS: Life Satisfaction. & & $\begin{array}{c}\text { PRACTICE In } \\
\text { CLINICAL PSYCH } \text { LOGY }\end{array}$
\end{tabular}

\& Molnar, 2019; Vishkin, Bloom, Schwartz, Solak \& Tamir, 2019).

Scholars also noted a negative relationship between procrastination and PWB. This result was consistent with those of the previous studies (Grunschel, Schwinger, Steinmayr \& Fries, 2016). Elevated procrastination decreases one's self-confidence and belief in one's abilities, leading to an adverse effect on their PWB (Duru \& Balkis, 2017). The goal selection process may be very beneficial in reducing procrastination. This is because it involves a focused process of goal pursuit that, e.g. achieves success faster by achieving sub-goals and increases subjects' PWB (Grunschel et al., 2016).

Therefore, the elderly feel better about their lives with proper ER. They also generate more optimism and hope for their lives and enjoy better social relationships. Concurrently, they feel independent and in control of the environment and live more purposefully (Chen et al., 2018). CER can be a significant determining factor in the health and QoL among individuals (Brown et al., 2020). The effectiveness of ER training on the QoL of the elderly can be explained by considering that ER helps individuals with managing emotions after experiencing stressful events (Perry et al., 2019). Individuals who use adaptive CER strategies when experiencing stress can effectively manage the intensity of their negative emotions by changing their assessments. When these negative emotions are effectively and adaptively regulated, a subject's resilience is likely to increase (Troy \& Mauss, 2011).

This study had limitations by removing which future studies can provide more evidence of the relationship between the studied variables. Some of the limitations of this research were its cross-sectional nature and the use of self-reporting tools. However, to better understand the relationship between these variables in old age, we require longitudinal studies. Furthermore, this study was conducted on the elderly in Tehran, which limits its generalization to the elderly in other areas. Thus, it is recommended that future research in nursing homes and other cities repeat this research. It is also suggested that in future studies, in addition to the self-report questionnaire, other methods, such as observation and field surveys be used.

\section{Conclusion}

The current study results signified the role of ER in increasing LS and PWB among the elderly. Therefore, using the obtained data, solutions can be provided to engage the elderly in useful activities and reduce procrastination among them to increase their LS and overall QoL. These goals could be accomplished by practical training and holding relevant workshops.

\section{Ethical Considerations}

\section{Compliance with ethical guidelines}

All ethical principles were observed in this study. The participants were informed about the purpose of the research and its implementation stages. They were also assured about the confidentiality of their information. Moreover, they were allowed to leave the study whenever they wanted, and if desired, the results of the research would be available to them.

\section{Funding}

This research did not receive any grant from funding agencies in the public, commercial, or non-profit sectors.

\section{Authors' contributions}

All authors contributed equally in preparing all parts of the present research.

\section{Conflict of interest}

The authors declared no conflict of interest. 


\section{References}

Aziz, K., Tariq, M., \& Zaidi, A. (2019). Biofilm development in L. fermentum under shear flow \& sequential GIT digestion. FEMS Microbiology Letters, 366(6), fnz064. [DOI:10.1093/ femsle/fnz064]

Bailey, P. E., Brady, B., Ebner, N. C., \& Ruffman, T. (2020). Effects of age on emotion regulation, emotional empathy, and prosocial behavior. The Journals of Gerontology: Series B, 75(4), 802-10. [DOI:10.1093/geronb/gby084] [PMID]

Bayani, A. A., Goudarzi, H., Bayani, A., \& Kouchaki, A. M. (2008). [The relationship between the religious orientation and anxiety and depression of university students (Persian)]. Journal of Fundamentals of Mental Health, 10(39), 209-14. [DOI:10.22038/JFMH.2008.1690]

Beigzade, M., Maleki, A., Siaddat, S. A., \& Malek-Mohammadi, M. (2013). Effect of combined application of phosphate fertilizers and phosphate solubilizing bacteria on yield and yield components of maize single cross 704. International Journal of Agriculture and Crop Sciences (IJACS), 6(17), 1179-85. https:/ / www.semanticscholar.org/

Benita, M., Benish-Weisman, M., Matos, L., \& Torres, C. (2020). Integrative and suppressive emotion regulation differentially predict well-being through basic need satisfaction and frustration: A test of three countries. Motivation and Emotion, 44(1) 67-81. [DOI:10.1007/s11031-019-09781-x]

Beutel, M. E., Klein, E. M., Aufenanger, S., Brähler, E., Dreier, M., \& Müller, K. W., et al. (2016). Procrastination, distress and life satisfaction across the age range - a German representative community study. PloS One, 11(2), e0148054. [DOI:10.1371/ journal.pone.0148054] [PMID] [PMCID]

Brown, T. A., Cusack, A., Berner, L. A., Anderson, L. K., Nakamura, T., Gomez, L., Trim, J., Chen, J. Y., \& Kaye, W. H. (2020). Emotion Regulation Difficulties During and After Partial Hospitalization Treatment Across Eating Disorders. Behavior therapy, 51(3), 401-12. [DOI:10.1016/j.beth.2019.07.002] [PMID] [PMCID]

Castel, A., Lluch, C., Ribas, J., Borràs, L., \& Moltó, E. (2017). Effects of a cognitive stimulation program on psychological well-being in a sample of elderly long-term care hospital inpatients. Aging \& Mental Health, 21(1), 88-94. [DOI:10.1080/13 607863.2015.1099033] [PMID]

Charles, S. T., \& Mavandadi, Sh. (2004). Social support and physical health across the life span: Socioemotional influences. In F. R. Lang, \& K. L. Fingerman (Eds.), Growing together: Personal relationships across the life span (pp. 240-267). Cambridge: Cambridge University Press. https://books.google. com/books?id=AggsqgQq_2EC\&dq

Chen, Sh., Chen, T., \& Bonanno, G. A. (2018). Expressive flexibility: Enhancement and suppression abilities differentially predict life satisfaction and psychopathology symptoms. Personality and Individual Differences, 126, 78-84. [DOI:10.1016/j. paid.2018.01.010]

Cordes, T., Bischoff, L. L., Schoene, D., Schott, N., VoelckerRehage, C., \& Meixner, Ch., et al. (2019). A multicomponent exercise intervention to improve physical functioning, cognition and psychosocial well-being in elderly nursing home residents: A study protocol of a randomized controlled trial in the PROCARE (prevention and occupational health in longterm care) project. BMC Geriatrics, 19(1), 369. [DOI:10.1186/ s12877-019-1386-6] [PMID] [PMCID]
Diener, E., Emmons, R. A., Larsen, R. J., \& Griffin, Sh. (1985) The satisfaction with life scale. Journal of Personality Assessment, 49(1), 71-5. [DOI:10.1207/s15327752jpa4901_13] [PMID]

Duru, E., \& Balkis, M. (2017). Procrastination, self-esteem, academic performance, and well-being: A moderated mediation model. International Journal of Educational Psychology, 6(2), 97119. [DOI:10.17583/ijep.2017.2584]

Farhadi, A., Barazandeh Choqaiee, S., Mokhtappour, H., Karami, Kh., \& Daraeezadeh, A. (2015). [Role of social support, spiritual well-being and self-efficasy in predicting the subjective well-being of the elderly (Persian)]. Aging Psychology, 1(2), 35-48. https://jap.razi.ac.ir/article_335.html

Feldman, F. (2019). An improved whole life satisfaction theory of happiness? International Journal of Wellbeing, 9(2), 1-7. [DOI:10.5502/ijw.v9i2.762]

Ferrari, J. R., \& Díaz-Morales, J. F. (2007). Procrastination: Different time orientations reflect different motives. Journal of Research in Personality, 41(3), 707-14. [DOI:10.1016/j. jrp.2006.06.006]

Gall, M. D., Borg, W. R., \& Gall, J. P. (2006). The methods of quantitative and qualitative research in education sciences and psychology. Trans. Nasr AR, Abolghasemi M, Bagheri KH, Pakseresht MJ, Khosravi Z, Shahani Yeilagh M. $2^{\text {nd }}$ edition. Tehran: SAMT Publications. http://opac.nlai.ir/opacprod/bibliographic/685798

Gomes, R., Gonçalves, S., \& Costa, J. (2015). Exercise, eating disordered behaviors and psychological well-being: a study with Portuguese adolescents. Revista Latinoamericana de Psicología, 47(1), 66-74. [DOI:10.1016/S0120-0534(15)30008-X]

Gross, J. J. (2002). Emotion regulation: Affective, cognitive, and social consequences. Psychophysiology, 39(3), 281-91. [DOI:10.1017/S0048577201393198] [PMID]

Grunschel, C., Schwinger, M., Steinmayr, R., \& Fries, S. (2016) Effects of using motivational regulation strategies on students' academic procrastination, academic performance, and well-being. Learning and Individual Differences, 49, 162-70. [DOI:10.1016/j.lindif.2016.06.008]

Huang, X., Lee, J. Ch. K., \& Yang, X. (2019). What really counts? Investigating the effects of creative role identity and self-efficacy on teachers' attitudes towards the implementation of teaching for creativity. Teaching and Teacher Education, 84, 5765. [DOI:10.1016/j.tate.2019.04.017]

Huxhold, O., Fiori, K. L., Webster, N. J., \& Antonucci, T. C. (2020). The strength of weaker ties: An underexplored resource for maintaining emotional well-being in later life. The Journals of Gerontology: Series B, 75(7), 1433-42. [DOI:10.1093/ geronb/gbaa019] [PMCID]

Katana, M., Röcke, Ch., Spain, S. M., \& Allemand, M. (2019) Emotion regulation, subjective well-being, and perceived stress in daily life of geriatric nurses. Frontiers in Psychology, 10, 1097. [DOI:10.3389/fpsyg.2019.01097] [PMID] [PMCID]

Kazemi, M., Fayyazi, M., \& Kaveh, M. (2010). [Investigation of procrastination prevalence and its causes among university managers and employees (Persian)]. Transformational Man agement Journal (Journal of Management Research), 2(4), 42-63. https://www.sid.ir/fa/journal/ViewPaper.aspx?ID=128475 
Klein, R. (1988). Inhibitory tagging system facilitates visual search. Nature, 334(6181), 430-1. [DOI:10.1038/334430a0] [PMID]

Michel, J. P., \& Sadana, R. (2017). "Healthy aging" concepts and measures. Journal of the American Medical Directors Association, 18(6), 460-4. [DOI:10.1016/j.jamda.2017.03.008] [PMID]

Ocal, K. (2016). Predictors of academic procrastination and university life satisfaction among Turkish sport schools students. Educational Research and Reviews, 11(7), 482-90. [DOI:10.5897/ ERR2016.2645]

Ouellet, C., Langlois, F., Provencher, M. D., \& Gosselin, P. (2019) Intolerance of uncertainty and difficulties in emotion regulation: Proposal for an integrative model of generalized anxiety disorder. European Review of Applied Psychology, 69(1), 9-18. [DOI:10.1016/j.erap.2019.01.001]

Pavot, W., \& Diener, E. (1993). The affective and cognitive context of self-reported measures of subjective well-being. Social Indicators Research, 28(1), 1-20. https:/ /link.springer.com/article/10.1007/BF01086714\#citeas

Perry, N. B., Donzella, B., Parenteau, A. M., Desjardins, Ch., \& Gunnar, M. R. (2019). Emotion regulation and cortisol reactivity during a social evaluative stressor: A study of post-institutionalized youth. Developmental Psychobiology, 61(4), 557-72. [DOI:10.1002/dev.21828] [PMID] [PMCID]

Ramia, I., \& Voicu, M. (2020). Life satisfaction and happiness among older Europeans: The role of active ageing. Social Indicators Research, July. [DOI:10.1007/s11205-020-02424-6]

Rees, G., Goswami, H., \& Bradshaw, J. (2010). Developing an index of children's subjective well-being in England. Retrieved from https://www.york.ac.uk/inst/spru/pubs/pdf/childswbSum.pdf

Ryan, R. M., \& Deci, E. L. (2017). Self-determination theory: Basic psychological needs in motivation, development, and wellness. New York: The Guilford Press. [DOI:10.1521/978.14625/28806]

Şahin, D. S., Özer, Ö., \& Yanardağ, M. Z. (2019). Perceived social support, quality of life and satisfaction with life in elderly people. Educational Gerontology, 45(1), 69-77. [DOI:10.1080/03 601277.2019.1585065

Scent, C. L., \& Boes, S. R. (2014). Acceptance and commitment training: A brief intervention to reduce procrastination among college students. Journal of College Student Psychotherapy, 28(2), 144-56. [DOI:10.1080/87568225.2014.883887]

Schouwenburg, H. C., \& Lay, C. H. (1995). Trait procrastination and the big-five factors of personality. Personality and Individual differences, 18(4), 481-90. [DOI:10.1016/01918869(94)00176-S]

Simpson, W. K., \& Pychyl, T. A. (2009). In search of the arousal procrastinator: Investigating the relation between procrastination, arousal-based personality traits and beliefs about procrastination motivations. Personality and Individual Differences, 47(8), 906-11. [DOI:10.1016/j.paid.2009.07.013]

Sirigatti, S., Penzo, I., Giannetti, E., Casale, S., \& Stefanile, C. (2016). Relationships between humorism profiles and psychological well-being. Personality and Individual Differences, 90 219-24. [DOI:10.1016/j.paid.2015.11.011]
Sirois, F. M., Nauts, S., \& Molnar, D. S. (2019). Self-compassion and bedtime procrastination: an emotion regulation perspective. Mindfulness, 10(3), 434-45. https://link.springer.com/ article/10.1007/s12671-018-0983-3

Steel, P. (2007). The nature of procrastination: A meta-analytic and theoretical review of quintessential self-regulatory failure. Psychological Bulletin, 133(1), 65-94. [DOI:10.1037/00332909.133.1.65] [PMID]

Tal, A., \& Kerret, D. (2020). Positive psychology as a strategy for promoting sustainable population policies. Heliyon, 6(4), E03696. [DOI:10.1016/j.heliyon.2020.e03696] [PMID] [PMCID]

Troy, A. S., \& Mauss, I. B. (2011). Resilience in the face of stress: Emotion regulation as a protective factor. In S. M. Southwick, B. T. Litz, D. Charney, \& M. J. Friedman (Eds.), Resilience and mental health: Challenges across the lifespan (pp. 30-44). Cambridge: Cambridge University Press. [DOI:10.1017/ CBO9780511994791.004]

Tuckman, B. W. (1991). The development and concurrent validity of the procrastination scale. Educational and Psychological Measurement, 51(2), 473-80. [DOI:10.1177/0013164491512022]

Vishkin, A., Bloom, P. B. N., Schwartz, Sh. H., Solak, N., \& Tamir, M. (2019). Religiosity and emotion regulation. Journal of Cross-Cultural Psychology, 50(9), 1050-74. [DOI:10.1177/0022022119880341]

Watakakosol, R., Ngamake, S. T, Suttiwan, P., Tuicomepee, A., Lawpoonpat, Ch., \& Iamsupasit, S. (2013). Factors related to successful aging in Thai elderly: A preliminary study. Journal of Health Research, 27(1), 51-6. https://he01.tci-thaijo.org/index.php/jhealthres/article/view/85757

Yazdanbakhsh, K. (2016). [Effects of life review on social adjustment of retirees' elderly persons (Persian)]. Aging Psychology, 1(3), 179-85. https://jap.razi.ac.ir/article_330.html

Zhao, J., Meng, G., Sun, Y., Xu, Y., Geng, J., \& Han, L. (2019). The relationship between self-control and procrastination based on the self-regulation theory perspective: The moderated mediation model. Current Psychology, October. [DOI:10.1007/ s12144-019-00442-3] 
This Page Intentionally Left Blank 